\title{
Single neuron activity-dependent signal processing
} Enrico Cataldo*1, Sara Arganda ${ }^{2,3}$, Raul Guantes ${ }^{2}$ and Gonzalo G de Polavieja ${ }^{3}$

\author{
Address: ${ }^{1}$ Dipartimento di Biologia, Unità di Fisiologia Generale, Università di Pisa, Italy, ${ }^{2}$ Instituto 'Nicolás Cabrera' de Física de Materiales, \\ Universidad Autónoma de Madrid, Spain and ${ }^{3}$ Instituto Cajal, Consejo Superior de Investigaciones Científicas, Spain \\ Email: Enrico Cataldo* - ecataldo@biologia.unipi.it \\ * Corresponding author
}

from Eighteenth Annual Computational Neuroscience Meeting: CNS*2009

Berlin, Germany. 18-23 July 2009

Published: 13 July 2009

BMC Neuroscience 2009, I0(Supp| I):PI I2 doi:I0.I |86/I47|-2202-I0-SI-PI I2

This abstract is available from: http://www.biomedcentral.com//47I-2202/I0/SI/PI I2

(C) 2009 Cataldo et al; licensee BioMed Central Ltd.

Activity in a neural network can affect both the synaptic strengths and the intrinsic electrical properties of neurons within the network. Changes of the intrinsic properties can enhance, reduce or stabilize the neural excitability. One of the activity-dependent regulatory mechanisms is the afterhyperpolarization, generally due to the activation of $\mathrm{K}^{+}$conductances and to a $\mathrm{Na}^{+} / \mathrm{K}^{+}$pump. In many neurons, the afterhyperpolarization is modified after a period of spike activity. In the mechanosensory $\mathrm{T}$ neurons of the leech, a prolonged electrical activity produces an increase of the afterhyperpolarization. This is believed to induce conduction block of spikes in several regions of the neuron, which in turn may decrease presynaptic invasion of spikes and thereby decrease transmitter release. To explore this possibility, we developed a multicompartment model of a T neuron [1]. The model incorporated empirical data describing the geometry of the cell and activity-dependent changes of the afterhyperpolarization. Simulations indicated that at some branching points activity-dependent increases of the afterhyperpolarization reduced the number of spikes transmitted from the receptive fields to the soma and beyond. Simulations also showed that the afterhyperpolarization could modulate transmission from the soma to the synaptic terminals, suggesting that it can regulate spike conduction within the presynaptic arborizations of the neuron, contributing to the synaptic depression correlated with increases in the afterhyperpolarization. In order to investigate how the afterhyperpolarization modulatory capabilities on transmission were dependent on the axonal geometry as well as on mem- brane properties, we developed [2] another multicompartment model of the mechanosensory cell, representing the reduced version of the model developed in [1]. The simulations suggested that channel kinetics influence the afterhyperpolarization-dependent modulation of spike conduction through points of impedance mismatch. The processing or conductive features of neurons seems to be determined in the first instance by the channel kinetics of the membrane and secondarily by the axonal geometry and activity-dependent processes and noise. We have also showed [3] that the role of the afterhyperpolarization induced by $\mathrm{Na}^{+} / \mathrm{K}^{+}$pump-activity, which consists in a slow reduction in excitability, is also involved in neuronal coding. We showed that the regulation of excitability by $\mathrm{Na}^{+} / \mathrm{K}^{+}$pump-activity is necessary for the neuron to make different responses depending on the statistical context of the stimuli. We investigate the role of membrane kinetics and input conductance mismatch in the adaptation of spike bursting to stimulus statistics.

\section{Acknowledgements}

GGP acknowledges financial support from $\mathrm{MCl}$ (Spain) and Biociencia program (CAM, Spain). RG acknowledges financial support from $\mathrm{MCl}$ (Spain).

\section{References}

I. Cataldo E, Brunelli M, Byrne JH, Av-Ron E, Cai Y, Baxter DA: Computational model of touch sensory cells (T Cells) of the leech: role of the afterhyperpolarization (AHP) in activity-dependent conduction failure. J Comput Neurosci 2005, I 8:5-24.

2. Cataldo E, Brunelli M, Av-Ron E, Cai Y, Baxter DA: Geometry, activity-dependent mechanisms, membrane kinetics and 
channel density distribution interplay in single neuron plasticity: a computational study. Biophys Rev \& Lett 2008, 3: I $35-155$.

3. Arganda S, Guantes R, de Polavieja GG: Sodium pumps adapt spike bursting to stimulus statistics. Nat Neurosci 2007, 10:1467-I473.

Publish with Bio Med Central and every scientist can read your work free of charge

"BioMed Central will be the most significant development for disseminating the results of biomedical research in our lifetime." Sir Paul Nurse, Cancer Research UK

Your research papers will be:

- available free of charge to the entire biomedical community

- peer reviewed and published immediately upon acceptance

- cited in PubMed and archived on PubMed Central

- yours - you keep the copyright

Submit your manuscript here:

http://www.biomedcentral.com/info/publishing_adv.asp 